\title{
PERCEPTUAL RESPONSES TO INFANT CRYING AFTER EEG BIOFEEDBACK ASSISTED STRESS MANAGEMENT TRAINING: IMPLICATIONS FOR PHYSICAL CHILD ABUSE
}

\author{
Paul D. Tyson and Karen B. Sobschak \\ Department of Psychology, Brock University, St. Catharines, Ontario, Canada
}

\begin{abstract}
The adult's perception of infant crying determines whether it is a source of stress and may be an antecedent to physical child abuse. The study had clients listen to infant crying and used stress management training to change their perceived arousal, anxiety, and evaluation of the crying. Fifteen nonparental female clients were randomly assigned to three groups who either had pretraining without stress, pretraining while listening to infant crying, or listened to yoked infant crying without pretraining. During the second stage all clients had stress management training while listening to infant crying. The clients' perceived anxiety and arousal elicited by crying were significantly diminished after stress management training and anxiety measures were strongly correlated with both perceived arousal and the clients' evaluation of infant crying. Although this is the first experiment applying biofeedback assisted stress management training to the perceptual responses and physiological arousal associated with infant crying, these results with inexperienced clients have implications for the prevention and treatment of parental stress and should encourage further research treating physical child abuse as a stress-related disorder.
\end{abstract}

Key Words - Infant crying, Child abuse, Stress management, EEG biofeedback.

\section{INTRODUCTION}

RECENT STUDIES HAVE examined the adult's perception of infant crying as a source of negative emotions and heightened physiological arousal (Frodi, 1985; Lazarus \& Folkman, 1984; Whipple \& Webster-Stratton, 1991). Infant crying is capable of arousing a variety of emotions, for example, the expected sympathetic response to the cries of an infant is frequently mixed with reports of aversion, anxiety, and physiological signs of stress (Boukydis, 1985). Research utilizing recorded cries has attempted to understand the negative emotional responses by examining characteristics of the listener (Frodi, 1985; Murray, 1985) and the acoustic features of different infant cries (Bisping, Steingrueber, Oltmann, \& Wenk, 1990; Frodi \& Senchak, 1990; Zeskind, 1983). In most studies, subjects of both genders ranging from 8 to 50 years felt distress, aversion, and arousal while listening to normal infant crying and their feelings usually became more intense when listening to premature, sick, or abnormal infants (Frodi, 1985; Frodi \& Senchak, 1990; Zeskind, 1983; Zeskind \& Lester, 1978). Physiologically, subjects showed increases in blood pressure, heart rate, and skin conductance while listening to the crying of human infants when compared to conditions of silence, or the crying of juvenile cats, orangutans, and aversive mechanical sounds (Boukydis \& Burgess, 1982; Murray,

Received for publication October 28, 1992; final revision received July 26, 1993; accepted July 27, 1993.

Requests for reprints should be addressed to Dr. Paul D. Tyson, Department of Psychology, Brock University, St. Catharines, Ontario, Canada L25 3A1. 
1985). This study is based on the premise that the negative emotions and physiological arousal evoked by normal infant crying are signs of stress.

Psychologically, stress occurs when there is an imbalance between the perceived demands of the situation and the capacity of an individual to cope with these demands (Lazarus \& Folkman, 1984; Lazarus, 1991). Infant crying sends an urgent, demanding signal to the caregiver which makes it a potential source of stress (Boukydis, 1985). The responsibility of raising a child can be extremely stressful especially when the infant is premature or colicky and the parents are inexperienced, lack coping skills, and receive little social support (Wolfe \& Jaffe, 1991). Parents concerned about their crying infant typically consult their physician who concentrates on the health of the infant, sometimes offers reassurance, but rarely assesses how the parents are coping (Wolfe, 1985). The relationship between parental stress and physical child abuse has received considerable attention in the literature (Whipple \& Webster-Stratton, 1991; Wolfe \& Jaffe, 1991). Studies have indicated that abusive mothers perceive infant crying to be particularly aversive and respond with greater physiological reactivity than nonabusive mothers (Disbrow, Doerr, \& Caulfield, 1977; Frodi \& Lamb, 1980; Wolfe, Fairbank, Kelly, \& Bradlyn, 1983). The perception of infant crying provides some insight into the amount of stress in the parent-child relationship.

What strategies can individuals and families use to prevent an aversive response to infant crying from developing into child abuse or neglect? Several intervention strategies have been developed to improve parenting skills, anger and stress management, and conditions in the family that affect parenting such as health or financial problems (Figley, 1989; Wolfe, 1987). However, in their evaluation of theories of physical child abuse, Tzeng, Jackson, and Karlson (1991) conclude that the degree to which these approaches can actually prevent child abuse or enhance family functioning is unknown. Various forms of stress management training have been suggested for the negative perceptions of infant crying found in abusive parents and atrisk individuals (Crowe \& Zeskind, 1992; Dietrich, Berkowitz, Kadushin, \& McGloin, 1990; Whipple \& Webster-Stratton, 1991; Wolfe \& Jaffe, 1991). On a small scale the results of stress management training for the prevention and treatment of abusive parents have been encouraging, but these techniques have never been applied to the perception and physiological arousal evoked by infant crying (Tzeng, Jackson, \& Karlson, 1991). Given that infant crying has the potential to be stressful and the high recidivism rates of parents abusing their children, both during and after traditional psychotherapeutic treatment (Cohen, 1979; Herrenkohl, Herrenkohl, Egolf, \& Seech, 1979), it would be prudent to first examine the effects of stress management training on clients who do not have children.

The hypothesis contends that stress management training will diminish the perceived anxiety, arousal, and negative evaluation of infant crying in nonparental clients. The behavioral and cognitive techniques used in this study have considerable empirical support with a variety of other stress-related disorders and family stressors (Figley, 1989). The specific techniques include relaxation training (Smith, 1985), systematic desensitization (Wolpe, 1982), and selfmonitoring exercises (Meichenbaum, 1985). Furthermore, when combined with biofeedback these techniques have been found to reduce the perceived stress and cortical (EEG) arousal associated with listening to aversive noise (Tyson, 1987). Biofeedback may be defined as the technique of using equipment to reveal to clients some of their internal physiological responses in the form of auditory or visual signals (Basmajian, 1983). With appropriate stress management training, clients can learn to change their physiological responses to stress by manipulating the feedback signals. Biofeedback can motivate clients to continue stress management training, provide concrete evidence that physiological responses to stress can be altered, and develop clients' self-control. In this experiment, the biofeedback assisted stress management techniques initially developed for stress related to occupational noise (Tyson \& Audette, 1979; Tyson, 
Table 1. Experimental Manipulation During Pretraining

\begin{tabular}{lccc}
\hline \multicolumn{1}{c}{ Group } & Biofeedback & Desensitization & Crying \\
\hline Pretraining without Stress & Yes & No & No \\
Pretraining with Stress & Yes & Yes & Yes \\
Stress without Pretraining & No & No & Yes \\
\hline
\end{tabular}

1982a; Tyson, 1987) will be applied to the unique pattern of auditory stimulation emitted by hungry infants (Lester \& Zeskind, 1982).

\section{METHODS}

\section{Subjects}

Fifteen female undergraduates from Brock University volunteered for a study on brain waves and infant crying and received credit to partially satisfy the requirements of an introductory psychology course. The 15 female clients ranging from 19 to 23 years were screened for any parental or biofeedback experience. Each client signed an informed-consent document and the study was approved by the Brock University human ethics committee.

\section{Experimental Design}

The clients were randomly assigned to three groups that were different during pretraining, but received the same stress management training during the second stage. During pretraining, the groups consisted of those who had:

1. stress management pretraining without crying, or

2. stress management pretraining with crying, or

3. crying without pretraining.

Following the procedures suggested by relaxation approaches (Smith, 1985), the first group practiced stress management training before being introduced to infant crying in the second stage. The second group, from the beginning, practiced stress management training while listening to infant crying and continued the same training during the second stage. The third group began training as a stress yoked control and listened to the loudness-modulated infant crying recorded from the second group. To insure the third group listened to the crying during pretraining, the clients were asked to follow the loudness changes in the infant crying by moving a lever on their chair and the movements were recorded on a polygraph to monitor any lapses in their attention to the crying.

During the second stage, all three groups had the same EEG biofeedback stress management training to diminish any stress associated with listening to infant crying and to measure the effects of pretraining. The first group had relaxation pretraining before the stressful infant crying was introduced during the second stage, the second group had training with the stress from the beginning, and the third group was habituated to infant crying before stress management training. During pretraining, the three groups were given different tasks and instructions, which are described below and summarized in Table 1.

\section{Stress Management Training}

During the tour of the laboratory all clients received a general introduction to psychological and physiological theories of stress (Lazarus, 1991; Mason, 1975). The female clients were 
asked to imagine that they had a baby with colic and the prognosis was 3 hours of crying a day for the next 3 months. This example was explained to the clients to illustrate the effects of stress on paying attention to their baby, their performance, and their problem solving (Tyson, 1982b).

In the two groups that had stress management pretraining, two mnemonic aids "Stop, look, and listen" and "Act and react" were employed to conceptualize the clients' tasks. The selfmonitoring exercises during the "Stop, look, \& listen" part of training were designed to practice attending to the crying without attempting to control what was happening or how they felt. The emphasis was on stopping the cycle of reciprocal aversive behavior between the adult and child by consciously interrupting what they are doing when the baby begins to cry (Burgess \& Richardson, 1984). By pausing and relaxing for a minute without immediately responding to the crying, the clients would practice what the Taoist call "not doing" (wuwei, Watts, 1957). The clients were instructed to "look" during the pause, observing and assessing the situation. Finally without acting on their perceptions or feelings, clients were asked to "listen" to themselves in order to detect conditioned emotional responses and defense mechanisms. In the second "Act \& react" part, clients applied their stress management techniques to practice self-control and effective coping behavior.

\section{Biofeedback and Relaxation Exercises}

Clients were asked several questions to assess their knowledge of biofeedback and the example of a bathroom scale was used to explain the basic principles of biofeedback. Clients were told that the sensor measured the minute electrical waves emitted from their brain (P4) and the feedback sound would get louder when they produced more alpha $(8-13 \mathrm{~Hz})$ activity (Tyson, 1987). Feedback in the first group was a harmonious sound, whereas in the second group, the feedback sound was the loudness of infant crying. The unique aspect of biofeedback in the latter group was that the client's physiological response to the crying controlled the loudness of the infant crying. The goal of the "Stop, look, \& listen" part of pretraining was to observe and develop an awareness of how their thoughts and feelings influenced their brain waves and clients were explicitly instructed not to attempt any relaxation or control strategy until the "Act \& react" phase of pretraining. Before the "Act \& react" phase, Jacobson's (1976) muscle relaxation exercises and Yoga breathing exercises (Smith, 1985) were explained to illustrate the kinds of strategies clients may want to experiment with to increase the loudness of the feedback sound. Biofeedback was used to motivate the clients and to assist them in evaluating the effectiveness of their relaxation training.

\section{Biofeedback Controlled Systematic Desensitization}

During the second stage, clients in all three groups had biofeedback training while listening to infant crying. First the clients were given Berkowitz's (1983) explanation of how an aversive stimulus like crying can evoke an aggressive response, then the discussion shifted to how they could extinguish negative emotional responses to infant crying by learning an incompatible relaxation response (Furedy \& Riley, 1982). Similar to Wolpe's (1958) systematic desensitization, the current experiment was designed to gradually expose clients to louder volumes of infant crying at a rate determined by the listener's physiological stress response. Instead of clients becoming more anxious when the infant's cries become louder, the biofeedback machine associates loud crying with becoming more relaxed. When clients have a strong physiological response to infant crying, the loudness of the crying is immediately reduced, giving clients a chance to practice relaxation, and to the degree the coping strategy was successful, the loudness of the infant crying gradually increased at a rate controlled by the client. In addition to crying 
being a source of stress, the loudness of the infant crying also provided clients with positive feedback for successfully coping with stress. Biofeedback controlled systematic desensitization, or biodesensitization, places clients in the position of controlling the extinction of their own stress response (Tyson, 1987).

\section{Infant Crying Tape and Biofeedback Sounds}

The recorded infant crying served two functions: first as a potentially stressful stimulus, and second as a biofeedback sound that signaled the clients' physiological response to the crying. As the feedback sound, the loudness of the infant crying reflected corresponding increases and decreases in the client's EEG alpha brain waves. The average volume of taped crying had to be carefully balanced to insure that clients could discriminate self-produced biofeedback changes in crying volume from naturally occurring rhythmic changes in the loudness of the infant crying. Using a Tascam (124AV simul-sinc) recorder, the crying tape for each 5-minute trial was composed of noise and distortion free 10 to 20 second crying samples to form a chorus of several infants crying simultaneously, which was balanced to form a relatively uniform intensity. The samples of crying were recorded before normal feeding times at the St. Catharine's General Hospital from 23 full-term 1- to 3-day-old infants. In the first biofeedback group, pretraining without stress, the auditory feedback sound was produced by synchronizing three sine wave frequencies using a Moog synthesizer and had been previously judged as not stressful and pleasant (Tyson, 1982a).

\section{Perçeptual Rating Scale}

After listening to recorded infant crying, clients were asked one question "How did you feel during the crying?' ' and rated their perceived feelings on three clearly marked dimensions: evaluation, anxiety, and arousal. Under each dimension were four bipolar 11-point scales and each scale had zero as the neutral center and the numbers 1-5 indicating degrees of intensity towards either side. The first scale under the Evaluation label was explained to the clients as an example (Positive 54321012345 Negative) where "1" would be slightly and "5" would be extremely positive or negative. The four scales under the Evaluation label were Positive/Negative, Pleasure/Pain, Aversion/Attraction, Approach/Avoid; under the Anxiety label were High/Low, Soothed/Annoyed, Distressed/Peaceful, Composed/Alarmed; and under the third Arousal label were High/Low, Sleepy/Alert, Muscles Tense/ Muscles Relaxed, and $\mathrm{Calm} / \mathrm{Excited}$. The three dimensions were derived from previous studies on the perception of noise (Tyson, 1987) by analyzing the canonical correlations between subjective experience and EEG variables and the scales including aversion, distress, and annoyance were derived from the literature on the perception of infant crying (Lester \& Boukydis, 1985).

\section{PROCEDURES}

While the clients were being prepared for their EEG recordings, the experimenter explained each step in the placement of electrodes, the rationale for the stress management training, and the experimental procedures to alleviate any anxiety about the situation. The instructions, baselines, and trials for each group of clients were also prerecorded to insure consistency within groups. The clients, tested individually, had a session that consisted of (a) EEG baselines and a 5-minute crying baseline followed by the perceptual rating scale, (b) three 5-minute trials with "Stop, look, \& listen" instructions, (c) three 5-minute trials with "Act \& react" 


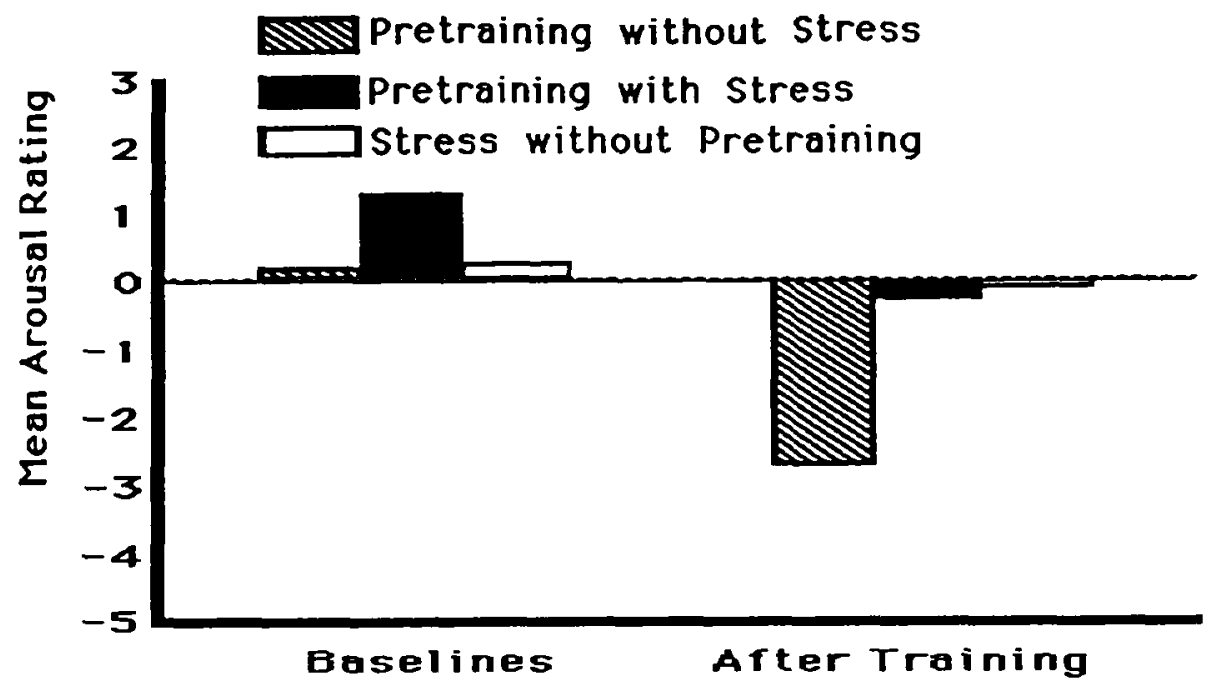

Figure 1. Perceived arousal ranging from plus to minus 5 during infant crying in the three experimental groups and after stress management training.

instructions, and in stage two (d) three 5-minute trials of stress management training while listening to infant crying followed by another perceptual rating scale.

\section{RESULTS}

Stress management training diminished the perceived arousal and anxiety associated with listening to infant crying in nonparental female clients. A $3 \times 2$ univariate analysis of variance between the three groups and the repeated (baseline/after training) measures variable was computed for the arousal, anxiety, and evaluation dimensions of the perceptual rating scale. A significant main effect was found between the baseline and the after training measures of arousal, $F(1,12)=19.44, p<.001$. All three groups reported feeling more aroused during the 5-minute infant crying baseline, and after training, reported lower levels of arousal. However, the perceived changes in arousal from baseline crying interacted with the type of training received by the three groups, $F(2,12)=4.12, p<.05$. The means associated with this significant interaction are plotted in Figure 1. A significant two-way interaction means that the simple main effects of the baseline/after factor are not the same for all three groups, and an analysis of these simple effects provides a method of determining which of these simple main effects are different (Keppel, 1982). On a 11-point scale ranging from plus to minus 5, the largest change $(-2.85)$ in arousal was significant $(F(1,12)=20.56, p<.001)$ in group one who practiced stress management training before being introduced to infant crying in the second stage of training. The second group who practiced stress management training with infant crying from the beginning of training had the next largest change $(-1.65)$ in arousal, $F(1,12)=6.89, p<.025$. The yoked control, who listened to infant crying before stress management training in the second stage, had the smallest change $(-.30)$ in arousal, which was not significant, $F(1,12)=.23, p=.64$.

The female clients' anxiety while listening to infant crying was reduced after stress management training. A significant main effect was found between the baseline measure of anxiety 


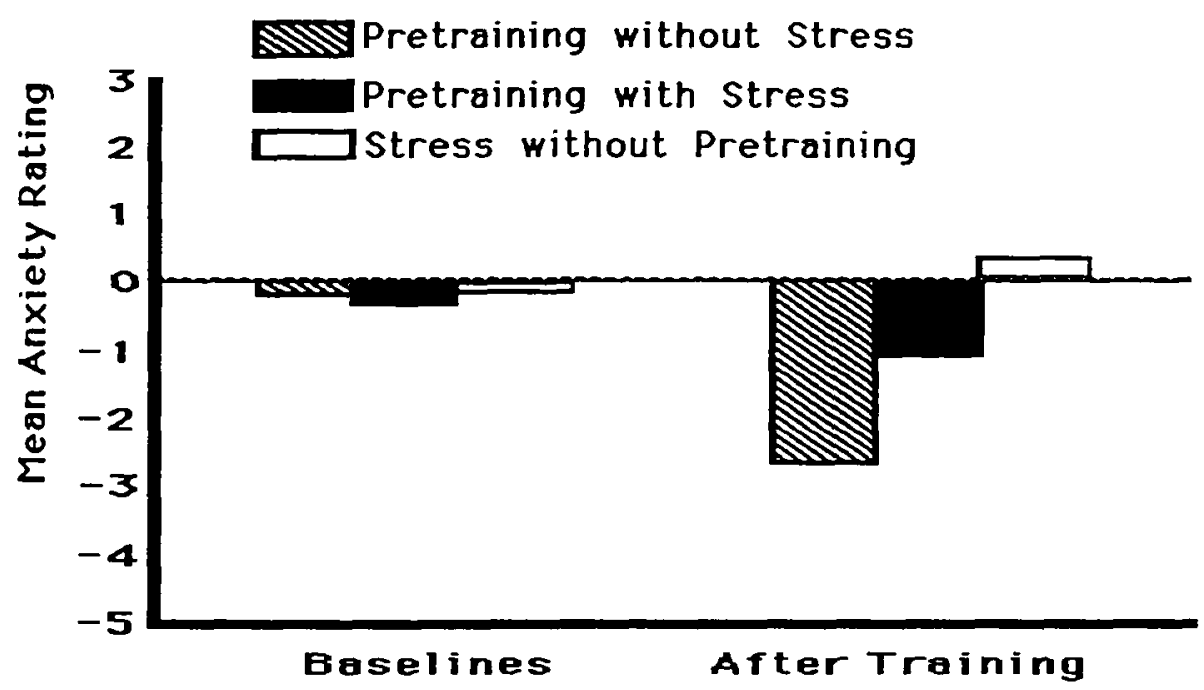

Figure 2. Perceived anxiety ranging from plus to minus 5 during infant crying in the three experimental groups and after stress management training.

and the clients' perception after training, $F(1,12)=4.78, p<.05$. The average of the three groups was significantly less than their baseline rating, however as illustrated in Figure 2 the changes in anxiety depended upon the type of training. Perceived anxiety interacted significantly $(F(2,12)=3.98, p<.05)$ with the type of training received by the clients and analyzing the simple effects (Keppel, 1982) revealed that the first group had the only significant change $(-2.54)$ in anxiety, $F(1,12)=11.22, p<.01$. The second group who began training listening to infant crying continued to lower $(-.70)$ their anxiety rating below baseline, but the change was not significant, $F(1,12)=.88, p=.37$. The yoked control clients, who were habituated to infant crying before stress management training, actually increased $(+.38)$ their anxiety rating, but the difference was not significant $(F(1,12)=.25, p=.63)$.

Although there were significant changes in the nonparental clients' perception of infant crying in the arousal and anxiety dimensions, there were no significant changes in the evaluation dimension. After training, the clients' evaluation of infant crying moved in a positive direction $(+.68)$ and as expected the largest change $(+1.55)$ was in the first group who practiced stress management training before listening to infant crying in the second stage. The magnitude of these nonsignificant changes in evaluation was not as large as, and the variability within groups was almost double, the arousal and anxiety dimensions.

The evaluation of infant crying was more resistant to being manipulated with stress management training than either perceived arousal or anxiety, but the clients' evaluation of crying was significantly correlated with the clients' perceived anxiety. After listening to 5 minutes of baseline infant crying, the clients' evaluation of how they felt during the crying was negatively correlated $(r=-.578, d f=13, p<.025)$ with their perceived anxiety, but not correlated $(r=.096)$ with how aroused the clients felt during the crying. After training, the evaluation of infant crying was also negatively correlated with anxiety $(r=-.477, d f=13$, $p<.05)$ and not significantly correlated $(r=-.13)$ with arousal. When the difference from baseline evaluation was correlated with the difference in anxiety after stress management training, the relationship between evaluation and anxiety changes became highly significant, $r=-.734, d f=13, p<.001$.

The clients' perceived anxiety associated with infant crying was also significantly correlated 
with their arousal. During the 5 minute baseline, the clients' rating of anxiety was positively correlated $(r=.446, d f=13, p<.05)$ with their perceived arousal and after training anxiety was highly correlated $(r=.783, d f=13, p<.001)$ with their arousal levels. The difference between baseline and after training arousal was also correlated $(r=.488, d f=13, p<.05)$ with anxiety changes, but again not significantly correlated $(r=.299)$ with changes in evaluation. In general, the anxiety dimension was significantly correlated with arousal and evaluation, but the clients' evaluation of infant crying was not correlated with their perceived arousal.

\section{DISCUSSION}

Based on incidence figures and long-term projections for North America, physical child abuse is becoming recognized as a problem that has broad implications for an increasingly violent society (Tzeng, Jackson, \& Karlson, 1991). There are major research projects investigating risk factors for child abuse and neglect such as economic deprivation, family dislocation, education, and cultural domination (Wolfe, 1987). Descriptive studies and home-based observational studies are exploring the correlations among a complex array of variables such as personality, social supports, family dysfunction, attitudes, expectations, and child-related experiences (Tzeng, Jackson, \& Karlson, 1991). The experimental results presented here, in conjunction with the work of other researchers investigating the perception of infant crying (Crowe $\&$ Zeskind, 1992; Frodi \& Senchak, 1990), should lead us to take a serious look at physical child abuse as a stress-related disorder. The cycle of aversive behavior between abusive parents and their children can be interrupted for a short time by using biodesensitization, biofeedback controlled desensitization, to reduce the arousal and anxiety associated with child-related cues (Berkowitz, 1990). In this experiment, clients responded positively to biofeedback because it gave them control over the loudness of the infant crying and control over the gradual extinction of their own stress response. The EEG biofeedback technology that linked the stressor to the client's physiological response could be applied to many other physiological responses, for example muscle tension, as long as the response was a good barometer of how successfully clients were coping with stress. Before biodesensitization can be applied to abusive parents who have aversive reactions to infants, it is important to first determine whether stress management can benefit people who have a history that puts them at-risk for child abuse (Casanova, Domanic, McCanne, \& Milner, 1992). Child abuse appears to be enmeshed in hierarchical levels of personal distress, family conflict, and social disadvantage, and thus any effort directed toward ameliorating stress should benefit the child (Wolfe, 1985).

In the past, biofeedback assisted stress management training has been shown to be effective with a variety of stress-related disorders (Middaugh, 1990; Tyson, 1987), but has never been applied to the negative emotions and physiological arousal generated by listening to hours of infant crying. Nonparental clients, in the present experiment, were asked to imagine that their colicky infant would be crying 3 hours a day for the next 3 months (Lester, Boukydis, GarciaColl, Hole, \& Peucker, 1992) and were given training in relaxation, self-monitoring, and biofeedback controlled systematic desensitization. The female clients demonstrated that stress management training can significantly diminish the perceived arousal and anxiety associated with listening to infant crying for a short time. Universally, clients felt that infant crying was arousing and many of them felt some anxiety while listening to the crying. The most significant effect of training was to dramatically reduce their perceived arousal, even when compared to yoked control clients who were habituated to the cries of an infant. As expected, clients' arousal was strongly correlated $(r=.783)$ with their perceived anxiety. In addition, the clients' evaluation of infant crying was also strongly correlated $(r=-.734)$ with their perceived 
anxiety, but interestingly, evaluation was not correlated with arousal. Consistent with studies of aversive noise (Tyson, 1982a, 1987), the EEG biofeedback assisted stress management techniques directly affected perceived arousal and anxiety, but contrary to our hypothesis training did not significantly affect the evaluation of infant crying. A more cognitive stress management approach, such as stress inoculation training (Meichenbaum, 1985), and longer training may have found more significant changes in the clients' appraisal and evaluation of an infant crying (Lazarus, 1991).

Clinical guidelines for stress management training are continually evolving and adapting to new clients, types of stress, and technical innovations (Futterman \& Shapiro, 1986; Wolfe, 1987). Effective programs should encourage flexibility in clients' coping repertoire by offering them a variety of techniques. However, the danger of diverse multilevel training is the potential overwhelming effect it may have on clients. When the clients in this study were probed with debriefing questions, those in group two who began training listening to infant crying felt overwhelmed by the number of tasks. The potential risks of listening to infant crying appear to be minimal in clients without children and, with more ręsearch on at-risk individuals and parents, stress management could become a therapeutic intervention for clients who are extremely aroused and anxious about infant crying (Kelly, 1983, Lester \& Boukydis, 1985). Infant crying does not cause physical child abuse, but as a source of stress may be a catalyst for a violent reaction. As a stress-related disorder, people dealing with child abuse should look for an imbalance between the perceived demands of being responsible for children and the ability of overwhelmed individuals, families, and communities to cope with the stress (Dietrich, Berkowitz, Kadushin, \& McGloin, 1990; Wolfe, 1987).

Ackndwledgement-The authors are grateful to Dr. Linda Rose-Krasnor and Janet Johnston for their helpful comments on this paper.

\section{REFERENCES}

Basmajian, T. V. (1983). Biofeedback: Principles and practices for clinicians. Baltimore, MD: Williams \& Wilkins. Berkowitz, L. (1983). Aversively stimulated aggression: Some parallels and differences in research with animals and humans. American Psychologist, 38, 1135-1144.

Berkowitz, L. (1990). On the formation and regulation of anger and aggression: A cognitive-neoassociationistic analysis. American Psychologist, 45, 494-503.

Bisping, R., Steingrueber, H. J., Oltmann, M., \& Wenk, C. (1990). Adult's tolerance of cries: An experimental investigation of acoustic features. Child Development, 61, 1218-1229.

Boukydis, C. F. Z. (1985). Perception of infant crying as an interpersonal event. In B. Lester \& Z. Boukydis (Eds.), Infant crying: Theoretical and research perspectives (pp. 187-216). New York: Plenum.

Boukydis, C. F. Z., \& Burgess, R. L. (1982). Adult physiological response to infant cries: Effects of temperament of infant, parental status, and gender. Child Development, 53, 1291-1298.

Burgess, R. L., \& Richardson, R. A. (1984). Coercive interpersonal contingencies as determinants of child abuse: Implications for treatment and prevention. In R. F. Dangel \& R. A. Polster (Eds.), Behavioral parent training: Issues in research and practice (pp. 239-259). New York: Guilford.

Casanova, G. M., Domanic, J., McCanne, T. R., \& Milner, J. S. (1992). Physiological responses to nonchild related stressors in mothers at risk for child abuse. Child Abuse \& Neglect, 16, 31-44.

Cohen, A. H. (1979). Essential elements of successful child abuse and neglect treatment. Child Abuse \& Neglect, 3, 491-496.

Crowe, H. P., \& Zeskind, P. S. (1992). Psychophysiological and perceptual responses to infant cries varying in pitch: Comparison of adults with low and high scores on the child abuse potential invitory. Child Abuse \& Neglect, 16, 19-29.

Dietrich, D., Berkowitz, L., Kadushin, A., \& McGloin, J. (1990). Some factors influencing abusers' justification of their child abuse. Child Abuse \& Neglect, 14, 337-345.

Disbrow, M. A., Doerr, H., \& Caulfield, C. (1977). Measuring the components of parents' potential for child abuse and neglect. Child Abuse \& Neglect, 1, 279-296.

Figley, C. R. (1989). Treating stress in families. New York: Brunner/Mazel. 
Frodi, A. M. (1985). When empathy fails: Aversive infant crying and child abuse. In B. Lester \& Z. Boukydis (Eds.), Infant crying: Theoretical and research perspectives (pp. 263-277). New York: Plenum.

Frodi, A. M., \& Lamb, M. D. (1980). Child abusers' responses to infant smiles and crys. Child Development, 51, $238-241$.

Frodi, A. M., \& Senchak, M. (1990). Verbal and behavioral responsiveness to the cries of atypical infants. Child Development, 61, 76-84.

Furedy, J. J., \& Riley, D. M. (1982). Classical and operant conditioning in the enhancement of biofeedback: Specifics and speculations. In L. White \& B. Tursky (Eds.), Clinical biofeedback: Efficacy and mechanisms (pp. 74-126). New York: Guilford.

Futterman, A. D., \& Shapiro, D. (1986). A review of biofeedback for mental disorders. Hospital and Community Psychiatry, 37, 27-33.

Herrenkohl, R. C., Herrenkohl, E. C., Egolf, B. P., \& Seech, M. (1979). The repetition of child abuse. How frequently does it occur? Child Abuse \& Neglect, 3, 67-72.

Jacobson, E. (1976). You must relax (5th ed.). New York: McGraw-Hill.

Kelly, J. A. (1983). Treating child abusive families: Intervention based on skills training principles. New York: Plenum.

Keppel, G. (1982). Design \& analysis: A researcher's handbook (2nd ed.) (pp. 302-333). Englewood Cliffs, NJ: Prentice Hall.

Lazarus, R. S. (1991). Progress on a cognitive-motivational-relational theory of emotion. American Psychologist, 46, 819-834.

Lazarus, R. S., \& Folkman, S. (1984). Stress, appraisal, and coping. New York: Springer.

Lester, B.M., \& Boukydis, C. F. Z. (1985). Infant crying: Theoretical and research perspectives. New York: Plenum Press.

Lester, B.M., \& Zeskind, P.S. (1982). A biobehavioral perspective on crying in early infancy. In H. Fitzgerald, B. M. Lester, \& M. W. Yogman (Eds.), Theory and research in behavioral pediatrics (pp. 133-180). New York: Plenum Press.

Lester, B. M., Boukydis, C. F. Z., Garcia-Coll, C. T., Hole, W., \& Peucker, M. (1992). Infantile colic: Acoustic cry characteristics, matemal perception of cry, and temperament. Infant Behavior and Development, 15, 15-26.

Mason, J. W. (1975). A historical view of the stress field. Journal of Human Stress, 1, 6-12, 22-36.

Meichenbaum, D. (1985). Stress inoculation training. New York: Pergamon.

Middaugh, S. J. (1990). On clinical efficacy: Why biofeedback does-and does not-work. Biofeedback and SelfRegulation, 15, 191-208.

Murray, A. (1985). Aversiveness is in the mind of the beholder: Perception of infant caring by adults. In B. Lester \& Z. Boukydis (Eds.), Infant crying: Theoretical and research perspectives (pp. 217-240). New York: Plenum Press.

Smith, J. C. (1985). Relaxation dynamics: Nine world approaches to self-regulation. Champaign, IL: Research Press.

Tyson, P. D. (1982a). The choice of feedback stimulus can determine the success of alpha feedback training. Psychophysiology, 11, 218-230.

Tyson, P. D. (1982b). A general systems theory approach to consciousness, attention, and meditation. Psychological Record, 32, 491-500.

Tyson, P. D. (1987). Task-related stress and EEG alpha biofeedback. Biofeedback and Self-Regulation, 12, $105-119$.

Tyson, P. D., \& Audette, R. (1979). A multivariate approach to the relationship between alpha waves and experience during feedback. Biofeedback and Self-Regulation, 4, 63-79.

Tzeng, O. C. S., Jackson, J. W., \& Karlson, H. C. (1991). Theories of child abuse and neglect: Differential perspectives, summaries, and evaluations. New York: Praeger Publishers.

Watts, A. W. (1957). The way of Zen. New York: Pantheon.

Whipple, E. E., \& Webster-Stratton, C. (1991). The role of parental stress in physically abusive families. Child Abuse \& Neglect, 15, 279-291.

Wolfe, D. A. (1985). Child-abusive parents: An empirical review and analysis. Psychological Bulletin, 97, $462-482$.

Wolfe, D. A. (1987). Child abuse: Implications for child development and psychopathology. Newbury Park, CA: Sage Publications.

Wolfe, D. A., \& Jaffe, P. (1991). Child abuse and family violence as determinants of child psychopathology. Canadian Joumal of Behavioural Science, 23, 282-299.

Wolfe, D. A., Fairbank, J., Kelly, J. A., \& Bradlyn, A. S. (1983). Child abusive parents' physiological responses to stressful and nonstressful behavior in children. Behavioral Assessment, 5, 363-371.

Wolpe. J. (1958). Psychotherapy by reciprocal inhibition. Stanford, CA: Stanford University Press.

Wolpe, J. (1982). The practice of behavior therapy (3rd ed.). New York: Plenum Press.

Zeskind, P. S. (1983). Cross-cultural differences in maternal perceptions of cries of low-and high-risk infants. Child Development, 54, 1119-1128.

Zeskind, P. S., \& Lester, B.M. (1978). Acoustic features and auditory perceptions of the cries of newborns with prenatal and perinatal complications. Child Development, 49, 580-589.

Résumé-La façon dont l'adulte perçoit les pleurs du jeune enfant détermine si ceux-ci peuvent devenir une source de tension et provoquer la maltraitance. Cette étude avait pour objet de faire écouter des pleurs d'enfant aux clients 
et d'utiliser des méthodes de gestion du stress afin d'adapter leur vécu de l'énervement ou de l'anxiété provoqués par les pleurs et l'évaluation de ces sentiments. Quinze femmes, qui n'étaient pas des mères ont été réparties de façon arbitraire dans 3 groupes. Le premier groupe avait été entrainté sans stress, le deuxième avait été entrainé et avait écouté les enfants pleurer, le troisième n'avait pas été entrainé tout en ayant écouté les pleurs d'enfant. Dans un deuxième temps tous les clients ont eu des séances de gestion de stress en écoutant des pleurs d'enfant. L'anxiété et l'irritation provoquées par les pleurs étaient diminuées de façon significative aprés l'entrainement de gestion du stress. Leś mesures de l'anxiété étaient corrélées avec l'irritation perçue par les clients ainsi que leur évaluation des pleurs. Malgré que cette expérience est la première à utiliser la gestion du stress par biofeedback en relation avec le vécu et les réactions physiologiques associées aux pleurs d'enfant, ces résultats avec des clients inexpérimentés ont des conséquences pour la prévention et le traitement de situations de stress chez les parents et devraient encourager les recherches à se centrer sur la maltraitance comme une pathologie liée au stress.

Resumen-La percepción del adulto de los gritos infantiles determinan si son una fuente de stress y pueden anteceder el abuso fisico contra los niños. Este estudio hizo que los clientes oyeran al infante llorando y se utilizó el entrenamiento para el manejo del stress para cambiar su respuesta perceptiva, su ansiedad y la evaluación de los gritos. Quince clientes no-parentales femeninas fueron asignadas al azar a tres grupos que tenían entrenamiento previo sin stress, entrenamiento previo mientras oían los gritos infantiles, o escuchaban los gritos infantiles sin entrenamiento previo. Durante la segunda etapa todas las clientes tenian entrenamiento para manejar el stress mientras oían el niño llorar. Después del entrenamiento para el manejo del stress las clientes disminuyeron significativamente su ansiedad y la respuesta provocada por los gritos y las medidas de ansiedad correlacionaron positivamente tanto con la respuesta percibida como con la evaluación de las clientes del llanto infantil. A pesar de que éste es el primer experimento aplicando el "biofeedback" en el entrenamiento para el manejo del stress a respuestas perceptuales y fisiológicas asociadas con el llanto infantil, estos resultados con clientes sin experiencia tienen implicaciones para la prevención y el tratamiento del stress parental y deben recomendarse más investigaciones sobre el abuso físico a los niños y niñas como un desórden relacionado con el stress. 